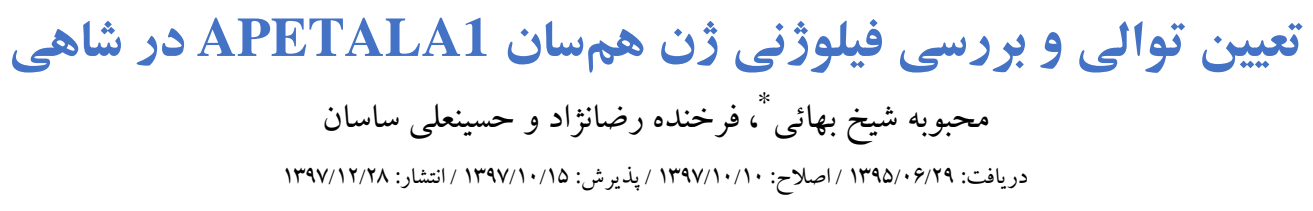

كروه زيستشناسى، دانشكده علوم، ، دانشگاه شهيد باهنر كرمان، كرمان، ايران

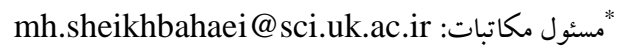

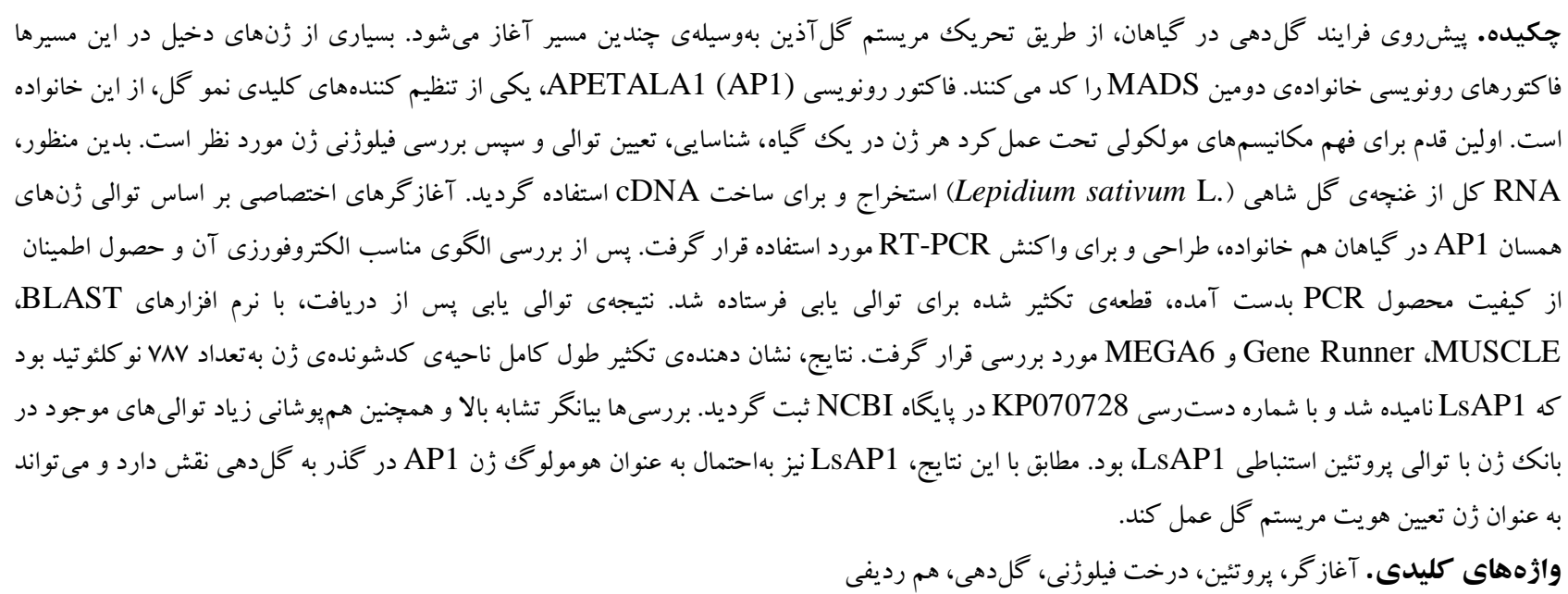

\title{
Sequencing and phylogenetic study of APETALA1 homologous gene in garden cress (Lepidium sativum L.)
}

Mahboubeh Sheikhbahaei*, Farkhondeh Rezanejad \& Hossein-Ali Sasan

Received 19.09.2016/ Revised 31.12.2018 / Accepted 05.01.2019 / Published 19.03.2019

Department of Biology, Faculty of Sciences, Shahid Bahonar University of Kerman, Kerman, Iran

*Correspondent author: mh.sheikhbahaei@sci.uk.ac.ir

\begin{abstract}
The flowering process in plants proceeds through the induction of an inflorescence meristem triggered by several pathways. Many of the genes associated with these pathways encode transcription factors of the MADS domain family. The MADS-domain transcription factor APETALA1 (AP1) is a key regulator of flower development. The first step in the understanding of molecular mechanisms under the function of each gene in a plant is identification, sequencing and phylogeny analysis of that gene. For this purpose, total RNA was isolated from the flower bud of garden cress (Lepidium sativum L.) and used for cDNA synthesis. The specific primers were designed on the basis of nucleotide sequence alignment of AP1 homologus genes from plants of the same family Brassicaceae and used in RTPCR. After observing its electrophoretic pattern and ensuring the quality of PCR product, the amplicon was sent for sequencing. Once the results of sequencing were received, the sequence was examined by BLAST, MUSCLE, Gene Runner and MEGA6 software. The results indicated the amplification of 787 nucleotides fragment namely LsAP1, which was recorded by accession number KP070728 in NCBI database. The studies showed high similarity and overlapping of gene bank sequences with LsAP1 illative protein. According to these results, LsAP1 might play a similar role as AP1 in flower induction and could act as a flower meristem identity gene in Lepidium sativum $\mathrm{L}$.
\end{abstract}

Keywords. Alignment, flowering, phylogenetic tree, primer, protein 
امروز محققان، زنهاى هومولو گك AP1 را در بسيارى از گياهان

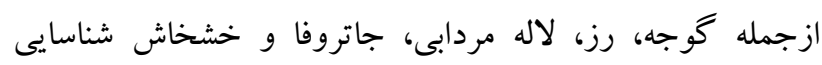
كردهاند ) M Burko et al., 2013; Kong et al., 2015; Tang et al.,

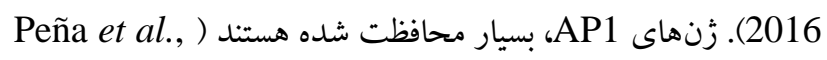

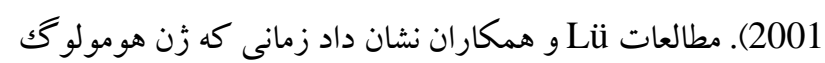

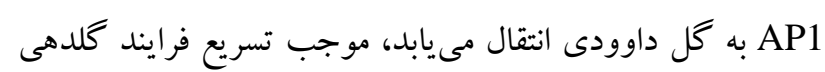

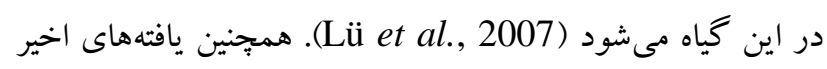

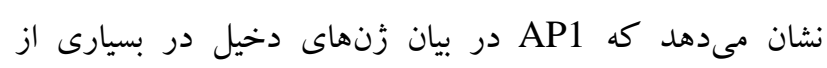

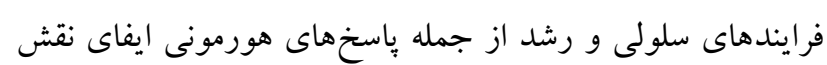

مى كند (Wellmer \& Riechmann, 2010). كونه مورد مطالعه در تحقيق حاضر، گياه شاهى با نام علمى .Bepidium sativum L)، از تيره شب بو (Brassicaceae)،

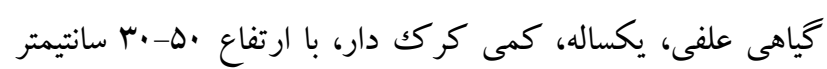

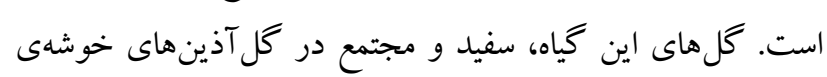

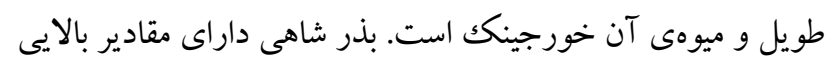
از آهن و كلسيم است. همجنين اين بذر بهدليل محتواى بالاى

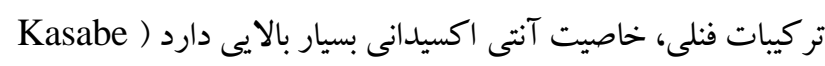

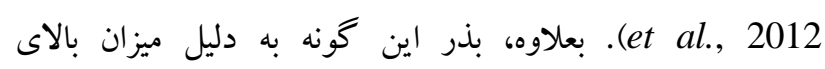

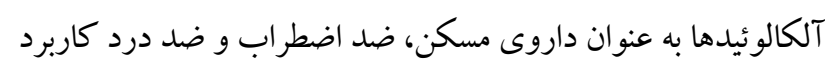

بسارى در طب سنتى دارد (Shukla et al., 2011). زن AP1 تاكنون در برخى از گونهاى تيره شب بو شناسايى و

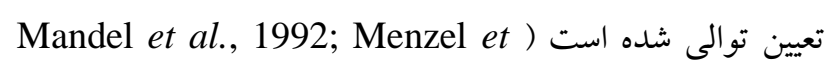
(al., 1995; Aikawa et al., 2010 مرورى ما نشان داد تاكنون در رابطه با شناسايى اين زن در زو مونه مذكور، مطالعه اى صورت نخرفته و يا گزارشى منتشر نشده است.

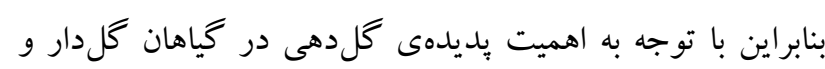

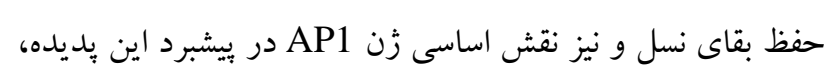

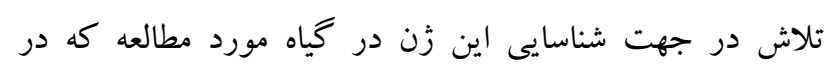

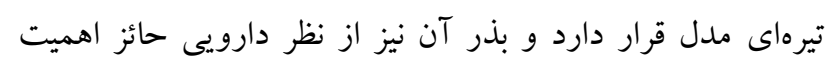

است مفيد و هلف تحقيق حاضر است.

\section{مواد و روشها}

بذر شاهى از شركت ياكان بذر اصفهان تهيه شد. در مرداد ماه،

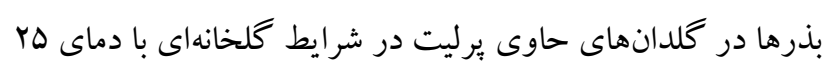

مقد مله مل در اثر بيان مجموعهاى از زنها اتفاق مى افتد و به عنوان

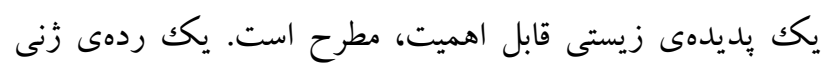

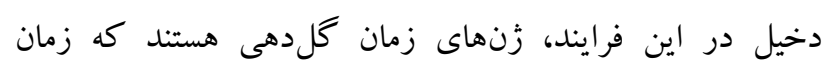

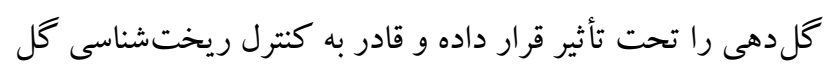

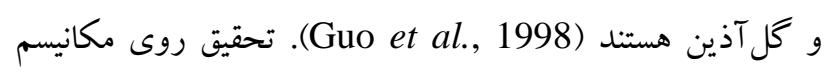
مولكولى و كنترل زنتيكى گل مههى در آرابيدويسيس نشان داده است كه APETALA1 (AP1) يكك زن تعيين هويت مريستم

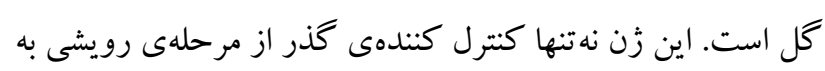

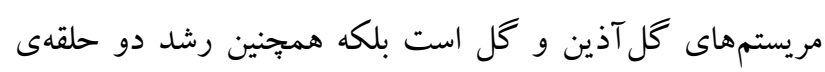

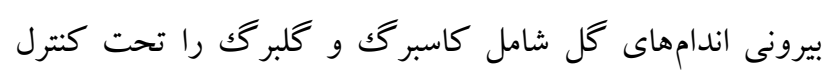

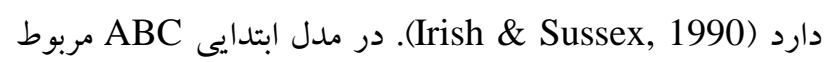

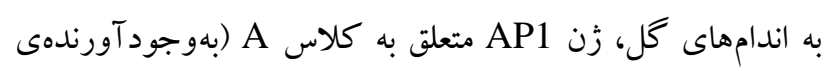

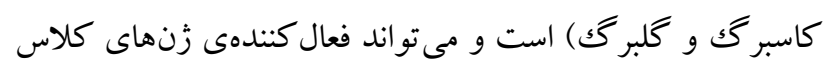

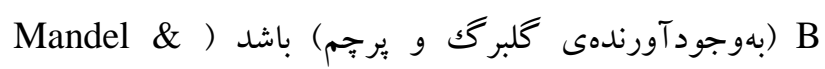
.(Yanofsky, 1995; Jack, 2004 آناليز بيانى در گونهى Nelumbo nucifera نشان داد كه AP1

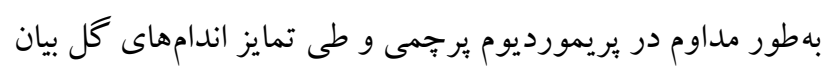

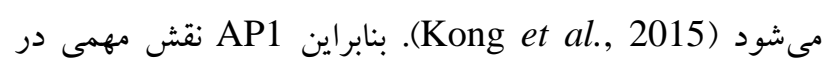

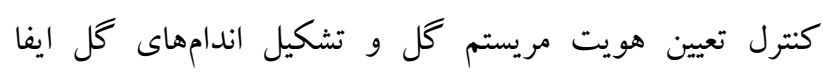
مى كند. در بررسى روى كلدهى آرابيدويسيس، (LFY) LEAFY

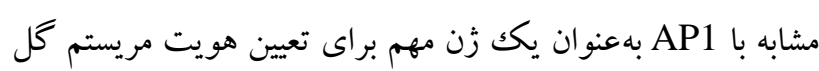

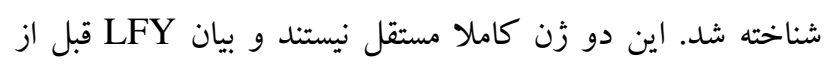

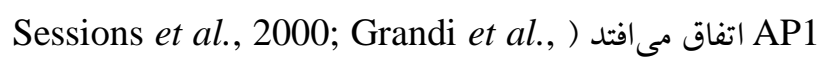
2012). بنابراين AP1 در تعيين هويت مريستم به عنوان زن بإيين دست LFY نقش دارد (Ng \& Yanofsky, 2001). بيان زود هنگام خود تحت تأثير LFY، بر روى ساير زنهاى تعيين

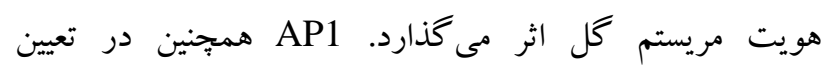

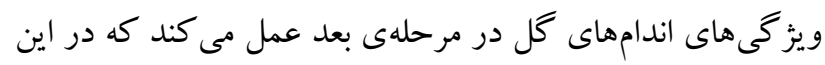
مرحله بهطور غير مستقيم تحت تأثير LFY است ( Mandel et .(al., 1992; Liljegren et al., 1999 زن AP1 در آرابيدويسيس روى كروموزومهاى شمارهى يكك،

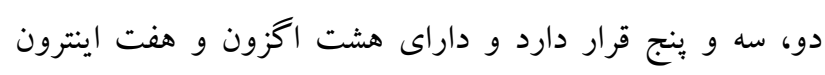

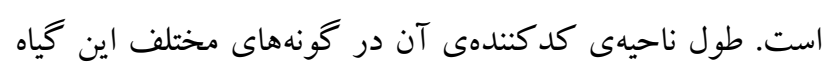

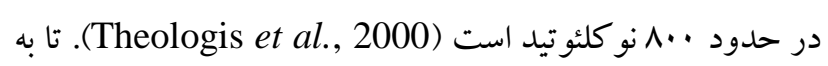




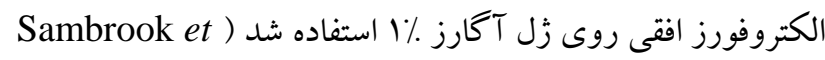
cDNA al., 2001 شركت فرمنتاز RevertAid First Strand cDNA Synt-) (hesis Kit

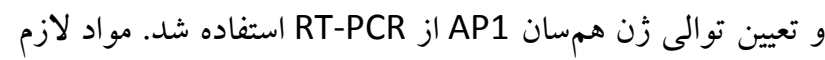

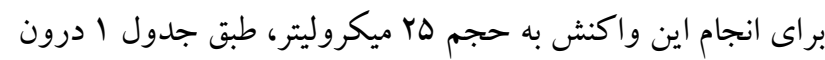

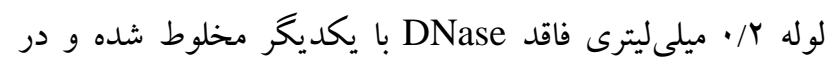

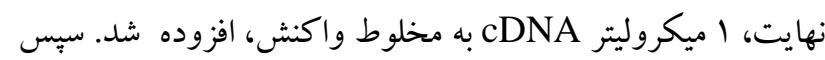
برنامهى ذكرشده در جدول Y با استفاده از دستگاه MJ Mini Personal Termal 1148) PTC ترموسايكلر مدل (Cycler BioRad, USA

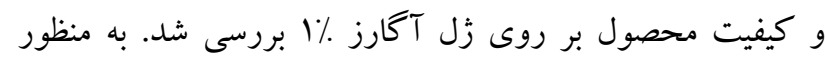

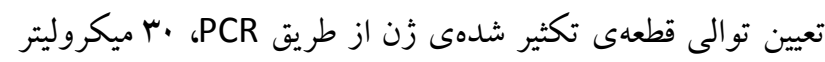

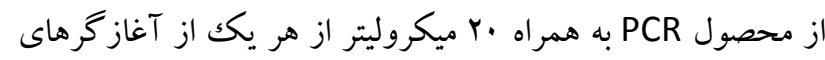

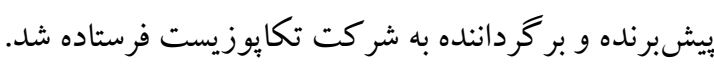

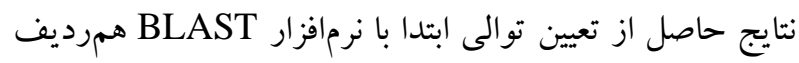

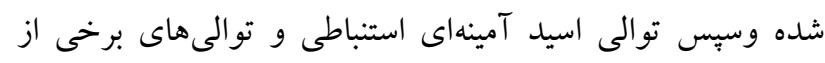

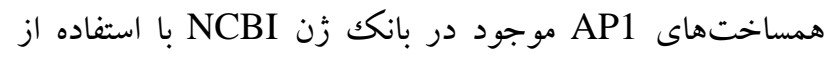

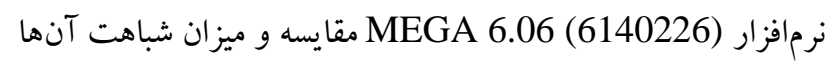

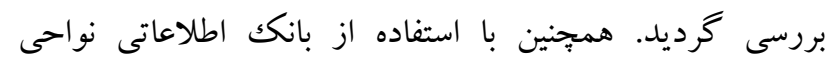

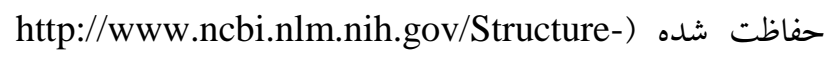
/cdd/cdd.shtml)، دومين هاى يروتئينى حفاظت شدهى همسان

$$
\text { AP1 }
$$

\section{جذب RNA در طول موج •وץ نانومتر 9.}

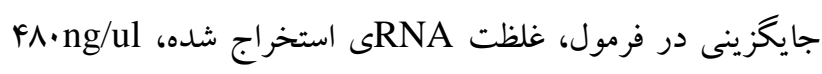

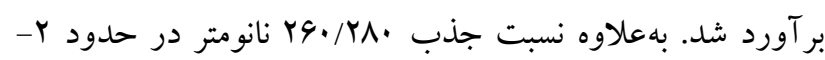

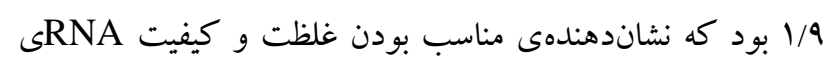

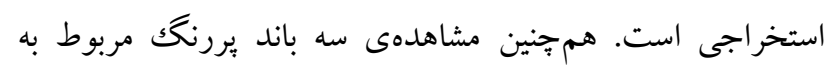
RNA

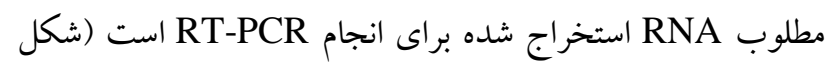

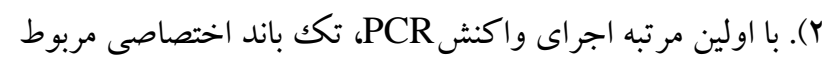
به تكثير طول كامل ناحيهى كد كنندهى زن به طول VAV نو كلئو تيد آند

$$
\text { روى زل آكارز مشاهده شد (شكل r). }
$$

درجه سانتيگر اد و دورهى نورى 19 ساعت نور و 1 ساعت تاريكى

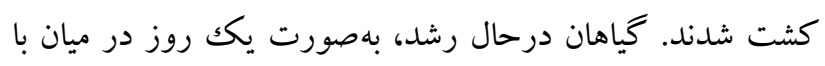

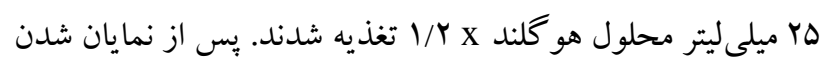

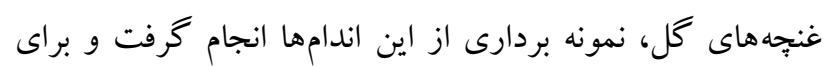
مطالعات مولكولى استفاده شد.

از آنجا كه توالى زن مورد نظر نامشخص بود، آغاز گرها بر اساس

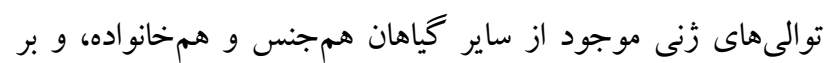

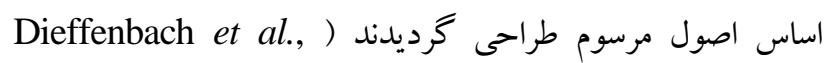

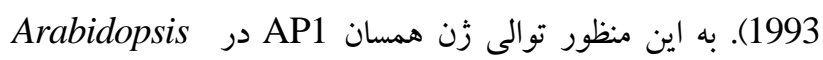
Arabidopsis ،thaliana (Accession no: Z16421.1) Camelina sativa halleri (Accession no: AB465587.1) Rorippa indica ‘(Accession no: XM010472583.1) Lepidium perfoliatum ،(Accession no: JX103196.1) Cardamine sp. ‘(Accession no: JX103194.1) Sinapis alba , (Accession no: AB372085.1) NCBI از بانكك زن (Accession no: X81480.1) (http://www.ncbi-.nlm.nih.gov)

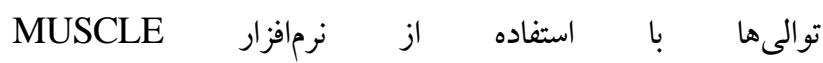
(https://www.ebi.ac.uk/Tools/-msa/muscle) كرفت. براساس نقاط حفاظت شدهى موجود و با مبنا قرار دادن ابتدا و

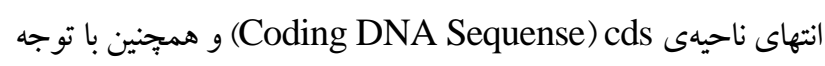
3' UTR و به نواحى (Untranslated Region) 5' UTR

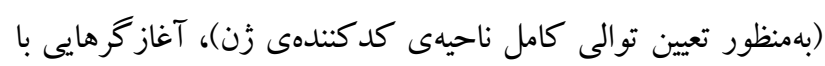

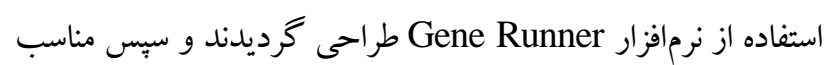

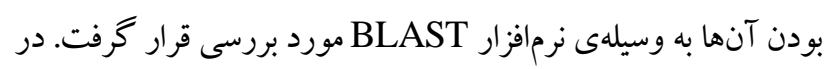

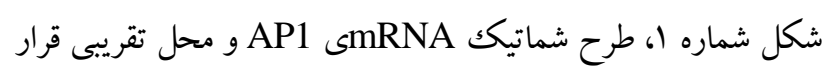

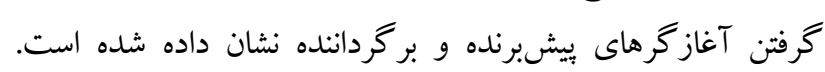

$$
\text { ساخت آغاز گرهاى طراحى شده توسط شركت بيشكام انجام شد. }
$$

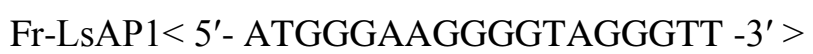
Rv-LsAP1< 5'- TGGAATTGTTTCATGCGG -3'> RNA كل از غنجِهاى گل با استفاده از محلول استخراج RNA GeneAll, RiboEx, Total RNA isolation solution, ) (Korea

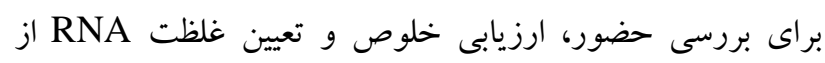

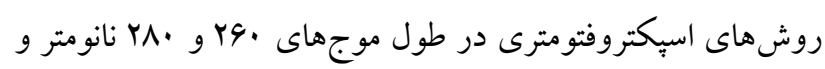




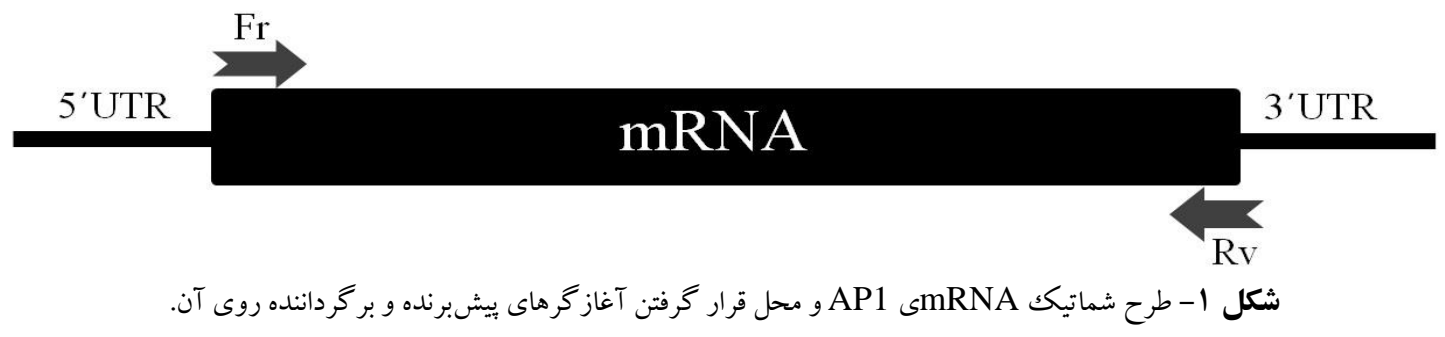

Fig. 1. Schematic illustration of AP1 mRNA and the position of the forward and reverse primers on it.

$$
\text { جدول 1- اجزاء مخلوط واكنش PCR در حجم Po P }
$$

Table 1. The PCR reaction mixture components in volume of $25 \mu 1$.

\begin{tabular}{|c|c|}
\hline مقدار مصرف در هر واكنش (ب1) & مواد مورد نياز \\
\hline $9 / \Delta \mu 1$ & آب دوبار تقطير ديونيزه \\
\hline هر كدام 1 ام & آغاز گرهاى Rv و Rr با غلظت · ب بيكومولار \\
\hline $\mid r / \Delta \mu 1$ & PCR MasterMix (Sina clone) \\
\hline$r \cdots \mathrm{ng}$ & cDNA \\
\hline
\end{tabular}

جدول r ب برنامهى جرخهاى واكنش زنجيرهى يليمراز.

Table 2. The cyclic program of PCR.

\begin{tabular}{|c|c|c|c|}
\hline تعداد جرخه & مرحله & حرارت (C) & زمان \\
\hline \multirow[t]{2}{*}{1} & واسرشتخى اوليه & 90 & هـ دقيقه \\
\hline & واسرشتخى & $9 F$ & ا دقيقه \\
\hline \multirow[t]{2}{*}{ rA } & اتصال & $\Delta V$ & ا دقيقه \\
\hline & طويلشدن & vr & ادقيقه \\
\hline 1 & طويل شدن نهايى & vr & V دقيقه V V V \\
\hline
\end{tabular}

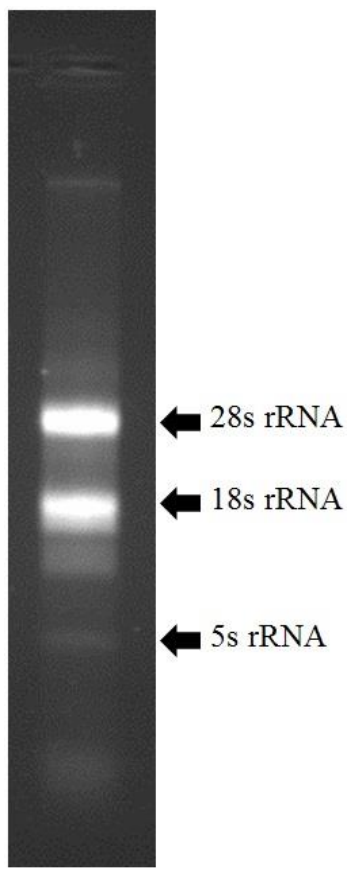

شكل r- نيمرخ الكتروفورزى RNA كل استخراج شده از غنجهى گل شاهى داراى سه باند واضح RNA

Fig. 2. The electrophoretic profile of extracted total RNA from Lepidium sativum flower bud consists of three clear bands of 28s rRNA, 18s rRNA and 5s rRNA. 


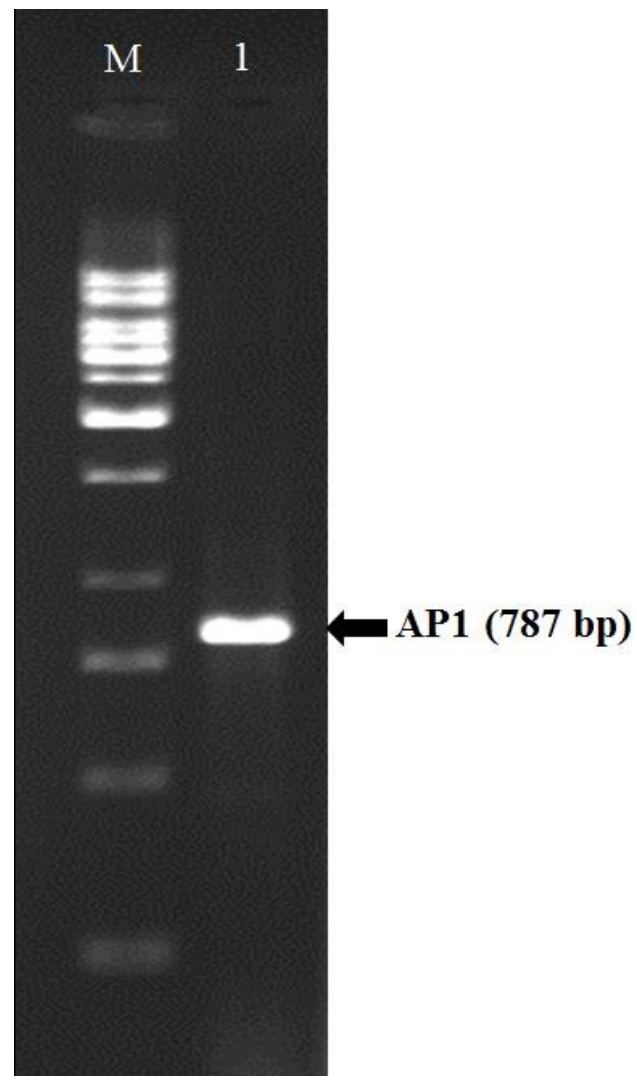

شكل س- نيمرخ الكتروفورزى محصول RT-PCR، نشان دهندهى تكثير طول كامل ناحيه كدكنندهى زن همسان AP1 در شاهى. 1: باند مربوط به قطعهى VNV

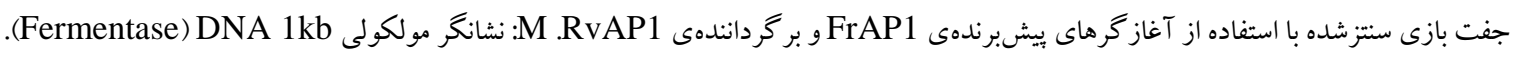

Fig. 3. The electrophoretic profile of RT-PCR product represents duplication of full length from cds AP1 homologus gene in Lepidium sativum. 1: The band associated with 787-bp fragment was synthesized using FrAP1 forward and RvAP1 reverse primers. M: 1kb DNA ladder (Fermentase).

http://www.ncbi.nlm.nih.gov/Structure/cdd/cdd.sht-) نشان داد كه توالى بروتئين LsAP1

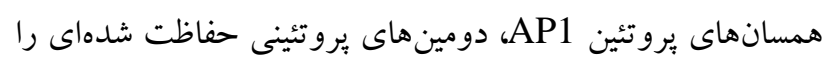

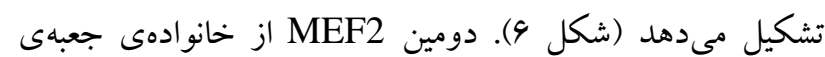
MADS-box) MADS يو كاريوتها است كه بهطور مستقيم به DNA متصل مى گردد و

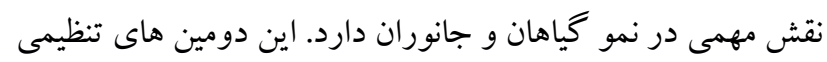

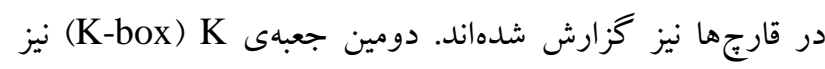
بهورت مجتمع با فاكتور بيانى SRF مشاهده ميشود و نقش آن آن

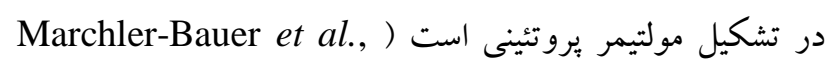

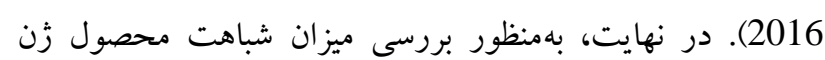

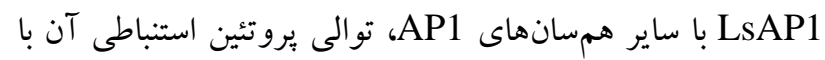

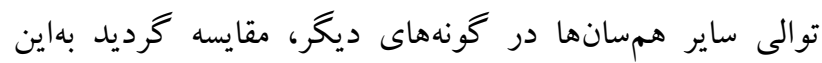

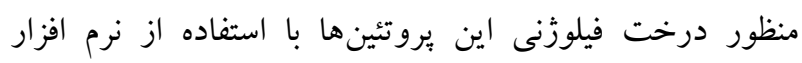
MEGA
محصول PCR حاصل از آغاز گرهاى Fr-AP1 و Rv-AP1 به

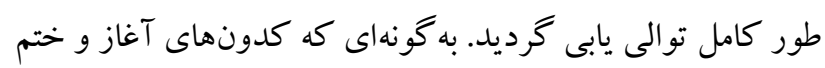

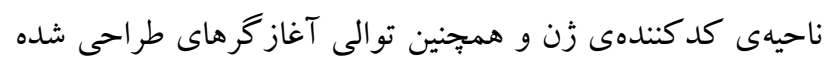

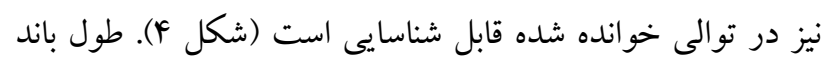

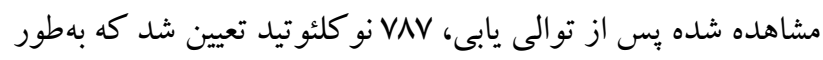

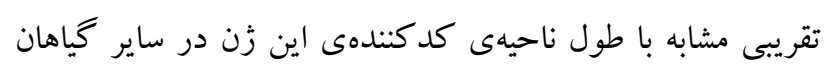
خانو ادهى شب بو كه از آنها براى طراحى آغاز كر استفاده كر كرديد، است. پِ از BLAST، مشخص شد كه نزديككترين توالى به إنه

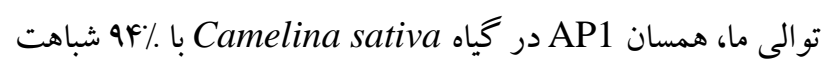

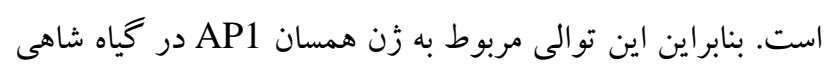

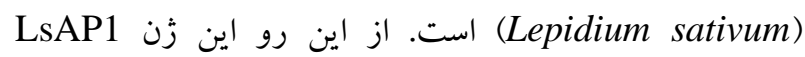

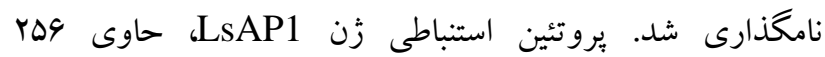
اسيدآمينه است (شكل ه). طول بروتئين LsAP1 تقريباً با ساير تهني يروتئينهاى همسان AP1 متعلق به خانوادهى شب بو برابر است.

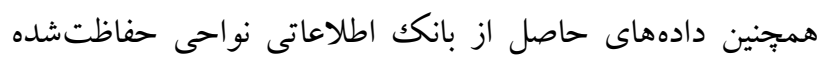




\section{FrAP}

ATGGGAAGGGGTAGGGTTCAATTGAAGAGGATAGAGAACAAGATCAATAGACAAGTGACATTCTCGAAAAGAAGAGCT GGTCTTTTGAAGAAAGCTCATGAGATCTCTGTTCTTTGTGATGCTGAAGTGGCTCTTGTTGTATTCTCTCATAAGGGCAAA CTCTTTGAATACTCCACTGATTCTTGTATGGAGAAAATACTTGAACGCTATGAGAGGTACTCTTACGCCGAGAGACAGCT TATTGCACCTGAATCTGACGTCAATACGAACTGGTCGATGGAGTATAACAGGCTTAAGGCTAAGATTGAGCTTTTGGAG AGGAACCAGAGGCACTATCTTGGGGAAGACTTGCAAGCAATGAGCTCTAAGGAGCTCCAGAATCTGGAGCAGCAGCTTG ACACTGCTCTTAAGCACATCCGCGCTAGAAAAAACCAACTTATGTACGAGTCCATCAATGAGCTTCAAAGAAAGGAGAA AGCCATACAGGAGCAAAACAGCATGCTTTCCAAACAGATTAAGGAGAGGGAGAAGATTCTAAGGGCGCAACAAGAGCA GTGGGAGCAACAGAACCATGGCCACAATATGCCTCCGCCTCTAGCACCGCCGCAGCAGCATCAGATTCAGCATCCTTAC ATGCTCTCTCATCAGCCATCTCCTTTTCTCAACATGGGTGGTCTGTATCAAGAAGATCCAATGGAAATGAGGAGGAACGA TCTCGATCTGTCACTTGAACCAGTTTACAACTGCAACCTTGGCTGCTTCGCCGCATGAAAACAATTGCAAAGGG RvAP شكل ع- توالى ثبت شده از ناحيهى كد كننده LsAP1 در بايخاه NCBI. ييكانها نشاندهندهى توالى آغاز گرهاى مورد استفاده است. همجنين كدونهاى آغاز و ختم، با كشيدن كادر دور آنها مشخص شدهاند.

Fig. 4. The NCBI registered sequence of LsAP1 cds region. Arrows show that primer sequences were used. Start and stop codons have been marked by boxes around them.

MGRGRVQLKRIENKINRQVTFSKRRAGLLKKAHEISVLCDAEVALVVFSHKGKLFEYSTDSCMEKILERYERYSYAERQLIAPESDVNT NWSMEYNRLKAKIELLERNQRHYLGEDLQAMSSKELQNLEQQLDTALKHIRARKNQLMYESINELQRKEKAIQEQNSMLSKQIKERE KILRAQQEQWEQQNHGHNMPPPLAPPQQHQIQHPYMLSHQPSPFLNMGGLYQEDPMEMRRNDLDLSLEPVYNCNLGCFAA

$$
\text { شكل 0- توالى يروتئين استباطى LsAP1. }
$$

Fig. 5. LsAP1 inferred protein sequence.

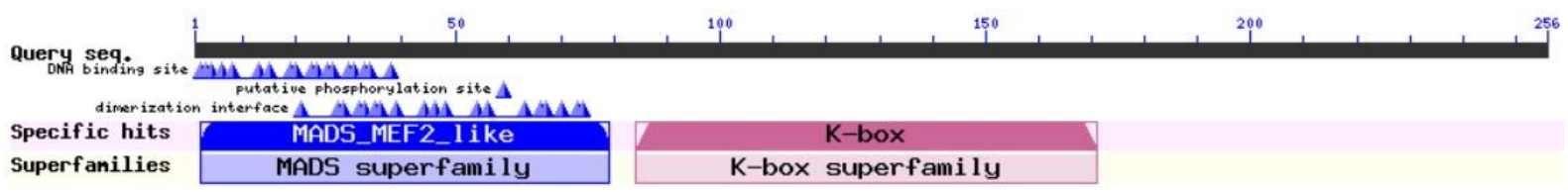

شكل 7- دومين هاى حفاظتشدهى LsAP1.

Fig. 6. LsAP1 conserved domains.

2004). توالى آمينواسيدى GsAP1 در Gene Bank با برنامهى BLAST

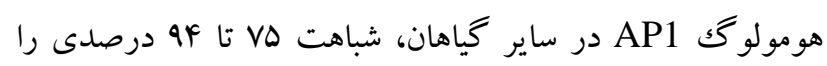
نشان داد. در اين ميان، ناحيهى جعبهى MADS داراى بالاترين ميزان شباهت و حفاظتشدكى بود. زن AP1 از طريق جعبهى قادر به اتصال به توالى خاصى از DNAS وسيله در جهت تنظيم بيان تعدادى از زنها عمل مى كند .(Suárez-López et al., 2001; Melzer et al., 2010)
بحث در سالهاى اخير، زنهاى هومولو گك AP1 در بسيارى از گياهان شناسايى شدهاند. AP1 براى تنظيم نمو كل ضرورى است كه اين مطلب بهطور مثال در كل ميمون و آرابيدويسيس ثابت شده است بت بـ Mandel \& Yanofsky, 1995; Liu et al., 2009) مطالعه، ما توالى كامل زن AP1 را در شاهى شناسايى و ويزگى هاى اين توالى را بررسى كرديم. توالى آمينواسيدى LsAP1 Jack, ) نشاندهندهى متعلق بودن آن به خانوادهى زنى AP1 استى 


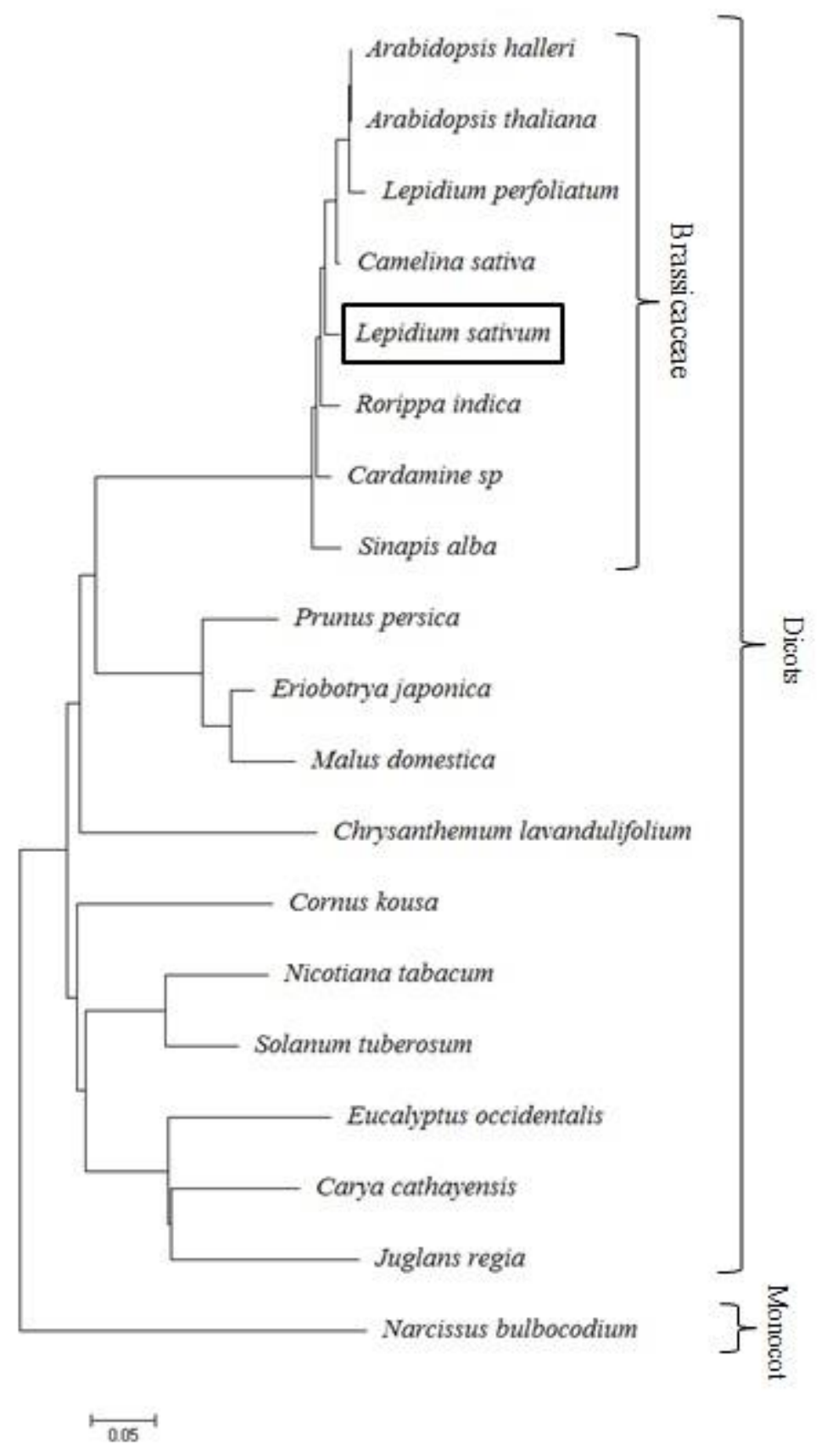

شكل Y- درخت فيلورنى گونهاى مختلف گياهى بر اساس ميزان شباهت در توالى بروتئين همسان AP1. در اين شكل، LsAP1 درون كادر قرار گرفته است.

Fig. 7. Phylogenetic tree from different plant species based on the AP1 protein sequence homology. In this figure, Lepidium sativum is placed in a box.

Riechmann et al., 1996; ) بروتئينى مشترك تشكيل مىدهند (CAULIFLOWER) CAL و AP1 .(Pelaz et al., 2001 نيز قادر به تشكيل دايمرهاى يروتئينى هستند ( Pelaz et al.,

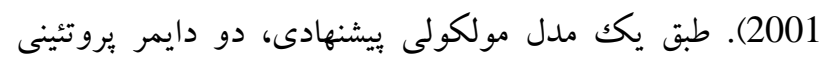

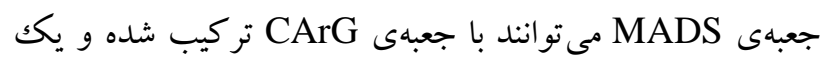
مدل مولكولى جهاربخشى از طريق برهمكنش بروتئينى ايجاد كنند

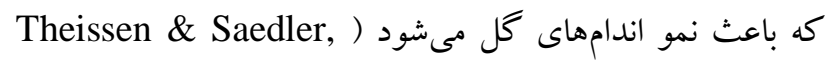

يروتئينهاى جعبهى MADS همجنين قادر به تشكيل دايمر و انجام Jack et al., 1992; Shore \& ) عمل كردهاى ديخر هستيند

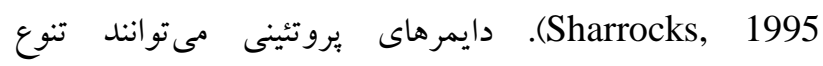
يروتئينهاى متصل شونده به DNA و تمايل بين كمبلكس

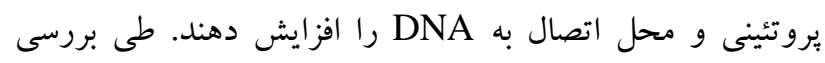
يروتئينهاى دايمرى جعبهى MADS در آرابيدويسيس، مشاهده

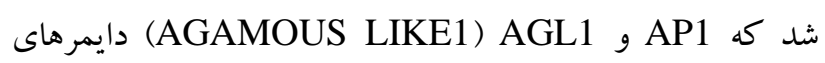




\section{REFERENCES}

Aikawa, S., Kobayashi, M.J., Satake, A., Shimizu, K.K. and Kudoh, H.J. 2010. Robust control of the seasonal expression of the Arabidopsis FLC gene in a fluctuating environment. - Proc. Natl. Acad. Sci. 107: 11632-11637.

Burko, Y., Shleizer-Burko S., Yanai, O., Shwartz, I., Zelnik, I.D., Jacob-Hirsch, J., Kela, I., EshedWilliams, L. and Ori, N. 2013. A role for APETALA1/FRU-ITFULL transcription factors in tomato leaf develo-pment. - Pl. Cell. 25: 2070-2083.

Dieffenbach, C., Lowe, T. and Dveksler, G. 1993. General concepts for PCR primer design. - PCR Methods Appl. 3: S30-S37.

Favaro, R., Pinyopich, A., Battaglia, R., Kooiker, M., Borghi, L., Ditta, G., Yanofsky, M., Kater, M., and Colombo, L. 2003. MADS-box protein complexes control carpel and ovule development in Arabidopsis. - Pl. Cell. 15: 2603-2611.

Grandi, V., Gregis, V. and Kater, M.M. 2012. Uncovering genetic and molecular interactions among floral meristem identity genes in Arabidopsis thaliana. Plant J. 69: 881-893.

Guo, H., Yang, H., Mockler, T.C. and Lin, C. 1998. Regulation of flowering time by Arabidopsis photoreceptors. - Science. 279: 1360-1363.

Honma, T. and Goto, K. 2001. Complexes of MADS-box proteins are sufficient to convert leaves into floral organs. - Nature 409: 525-529.

Irish, V.F. and Sussex, I.M. 1990. Function of the apetala-1 gene during Arabidopsis floral development. - Pl. Cell. 2: 741-753.

Jack, T. 2004. Molecular and genetic mechanisms of floral control. - P1. Cell. 16: S1-S17.

Jack, T., Brockman, L.L. and Meyerowitz, E.M. 1992. The homeotic gene APETALA3 of Arabidopsis thaliana encodes a MADS box and is expressed in petals and stamens. - Cell 68: 683-697.

Kasabe, P.J., Patil, P.N., Kamble, D.D. and Dandge, P.B. 2012. Nutritional, elemental analysis and antioxidant activity of garden cress (Lepidium sativum L.) seeds. - Int. J. Pharm. Pharm. Sci. 4: 392-395.

Kong, D., Shen, X., Guo, B., Dong, J., Li, Y. and Liu, Y. 2015. Cloning and expression of an APETALA1-like gene from Nelumbo nucifera. - Genet. Molec. Res. 14: 6819 .

Liljegren, S.J., Gustafson-Brown, C., Pinyopich, A., Ditta, G.S. and Yanofsky, M.F. 1999. Interactions among APETALA1, LEAFY, and TERMINAL FLOWER1 specify meristem fate. - Pl. Cell. 11: 1007-1018.

Liu, C., Xi, W., Shen, L., Tan, C. and Yu, H. 2009. Regulation of floral patterning by flowering time genes. - Dev. Cell. 16: 711-722.

Lü, J., Wu, Y., Sun, L. and Zhang, Q. 2007. Genetic transformation of Chrysanthemum morifolium cv.'Yu Ren Mian'with AP1 gene mediated by Agrobacterium tumefaciens. - Sci. Silvae Sin. 43: 128-132.

Mandel, M.A., Gustafson-Brown, C., Savidge, B. and Yanofsky, M.F.J.N. 1992 Molecular characterization
2001). بنابراين در آرابيدويسيس، دايمرهاى AP1/AP2 و قادر به تشكيل تترامرى هستند كه كنترل كنندهى SEP/AP1 تشكيل كاسبر گهاست و دايمرهاى AP3/AP1 و SEP/AP1 تترامرى تشكيل مىدهند كه تشكيل گلبر گها را تحت كنترل دارد (Honma \& Goto, 2001; Favaro et al., 2003) يلى مريزاسيون بروتئينى براى كنترل بيان زن مهم است و زنهاى جعبهى MADS نقش مهمى در نمو كل ايفا مى كنند. در اينجا ما يكك توالى جعبهى MADS را شناسايى كرديم كه در تنظيم نمو كل دخيل است. آناليز توالى LsAP1 نشان داد كه اين توالى توالى علاوه بر داشتن جعبهى MADS، شباهت بالايى نيز با AP1ها در

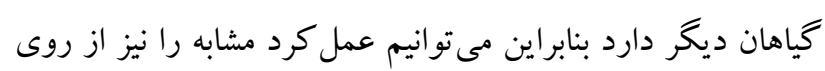
تشابه ساختارى حدس بزنيم (Xu et al., 2011).

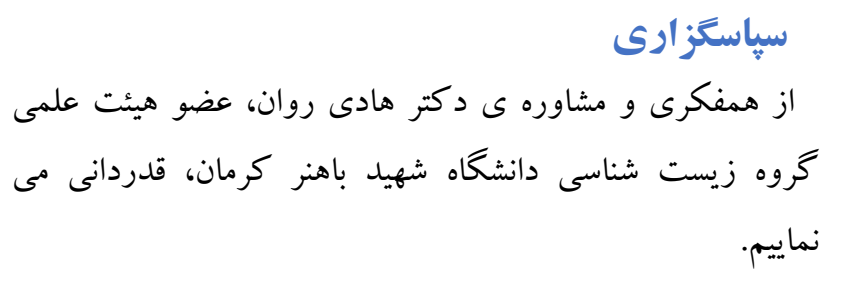


of the Arabidopsis floral homeotic gene APETALA1. Nature 360: 273-277.

Mandel, M.A., and Yanofsky, M.F. 1995. A gene triggering flower formation in Arabidopsis. - Nature 377: 522-524.

Marchler-Bauer, A., Bo, Y., Han, L., He, J., Lanczycki, C.J., Lu, S., Chitsaz, F., Derbyshire, M.K., Geer, R.C. and N.R. Gonzales. 2016. CDD/SPARCLE: functional classification of proteins via subfamily domain architectures. - Nucl. Acids Res. 45: D200D203.

Melzer, R., Wang, Y. and Theißen, G. 2010. The naked and the dead: the ABCs of gymnosperm reproduction and the origin of the angiosperm flower. - Semin. Cell Dev. Biol. 21: 118-128.

Menzel, G., Apel, K. and Melzer, S. 1995. Isolation and analysis of SaMADS C, the APETALA 1 cDNA homolog from mustard. - Pl. Physiol. 108: 853.

Mibus, H., Heckl, D. and Serek, M. 2011. Cloning and characterization of three APETALA1/FRUITFULLlike genes in different flower types of Rosax hybrida L. - J. Pl. Growth Regulat. 30: 272-285.

Ng, M. and Yanofsky, M.F. 2001. Activation of the Arabidopsis B class homeotic genes by APETALA1. - Pl. Cell. 13: 739-753.

Ó'Maoiléidigh, D.S., Graciet, E. and Wellmer, F. 2014. Gene networks controlling Arabidopsis thaliana flower development. - New Phytol. 201: 16-30.

Pabón-Mora, N., Ambrose, B.A. and Litt, A. 2012. Poppy APETALA1/FRUITFULL orthologs control flowering time, branching, perianth identity, and fruit development. - Pl. Physiol. 158: 1685-1704.

Pelaz, S., Gustafson-Brown, C., Kohalmi, S.E., Crosby, W.L. and Yanofsky, M.F. 2001. APETALA1 and SEPALLATA3 interact to promote flower development. - Plant J. 26: 385-394.

Peña, L., Martín-Trillo, M., Juárez, J., Pina, J.A., Navarro, L. and Martínez-Zapater, J.M. 2001. Constitutive expression of Arabidopsis LEAFY or APETALA1 genes in citrus reduces their generation time. - Nat. Biotechnol. 19: 263-267.

Riechmann, J.L., Krizek, B.A. and Meyerowitz, E.M. 1996. Dimerization specificity of Arabidopsis MADS domain homeotic proteins APETALA1, APETALA3, PISTILLATA, and AGAMOUS. - Proc. Natl. Acad. Sci. 93: 4793-4798.

Sambrook, J., Russell, D.W. and Russell, D.W. 2001. Molecular cloning: a laboratory manual (3-volume set). - Cold spring harbor laboratory press, New York, 2: 300
Sessions, A., Yanofsky, M.F. and Weigel, D. 2000. Cellcell signaling and movement by the floral transcription factors LEAFY and APETALA1. Science 289: 779-781.

Shore, P. and Sharrocks, A.D. 1995. The MADS-box family of transcription factors. - Eur. J. Biochem. 229: 1-13.

Shukla, A., Singh, C.S. and Bigoniya, P. 2011. Phytochemical and CNS activity of Lepidium sativum Linn seeds total alkaloid. - Der Pharmacia Lett. 3: 226-237.

Suárez-López, P., Wheatley, K., Robson, F., Onouchi, H., Valverde, F. and Coupland, G. 2001. CONSTANS mediates between the circadian clock and the control of flowering in Arabidopsis. - Nature. 410: 11161120.

Tang, M., Tao, Y.B. and Xu, Z.F. 2016. Ectopic expression of Jatropha curcas APETALA1 (JcAP1) caused early flowering in Arabidopsis, but not in Jatropha. - Peer J. 4: e1969.

Theissen, G. and Saedler, H. 2001. Plant biology: floral quartets. - Nature. 409: 469-471.

Theologis, A., Ecker, J.R., Palm, C.J., Federspiel, N.A., Kaul, S., White, O., Alonso, J., Altafi, H., Araujo, R. and Bowman, C.L. 2000. Sequence and analysis of chromosome 1 of the plant Arabidopsis thaliana. Nature 408: 816-820.

Wellmer, F. and Riechmann, J.L. 2010. Gene networks controlling the initiation of flower development. Trends Genet. 26: 519-527.

Xu, Z., Ali, Z., Yi, J., He, X., Zhang, D., Yu, G., Khan, A., Khan, I. and Ma, H. 2011. Expressed sequence tag-simple sequence repeat-based molecular variance in two Salicornia (Amaranthaceae) populations. Genet. Molec. Res. 10: 1262-1276.

$$
* * * * *
$$

How to cite this article:

Sheikhbahaei, M., Rezanejad, F. and Sasan, H.A. 2019. Sequencing and phylogenetic study of APETALA1 homologous gene in garden cress (Lepidium sativum L.). - Nova Biol. Reperta 5: 411419.

$$
\begin{aligned}
& \text { شيخبهائى، م.، رضانزاد، ف. و ساسان، ح.ع. لوسا. تعيين توالى و } \\
& \text { بررسى فيلوزنى زن همسان APETALA1 در شاهى. - يافتهاى نوين }
\end{aligned}
$$

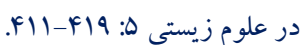

